\title{
Tribological performance of polymer composites used in electrical engineering applications
}

\author{
ZAFER DEMIR \\ Anadolu University, Eskisehir, Turkey \\ MS received 28 December 2011; revised 13 March 2012
}

\begin{abstract}
Sliding wear performance of $20 \%$ mica-filled polyamide 6 (PA6 $+20 \%$ mica) and $20 \%$ short glass fibrereinforced polysulphone (PSU + 20 GFR) polymer composites used in electrical applications were investigated using a pin-on-disc wear test apparatus. Two different disc materials were used in this study. These are AISI 316 L stainless steel and 30\% glass fibre-reinforced polyphenylenesulphide (PPS + 30\% GFR) polymer composite. Wear test was carried out at 10, 20 and $30 \mathrm{~N}$ applied load values and $0.5 \mathrm{~m} / \mathrm{s}$ sliding speed and at ambient temperature and humidity. Different combinations of rubbing surfaces were examined and friction coefficient and specific wear rate values were obtained and compared. For two material combinations used in this investigation, the coefficient of friction shows insignificant sensitivity to applied load values and large sensitivity to material combinations. For specific wear rate, PA6 + $20 \%$ mica composite has shown insensitivity to change in load, speed and materials combination while PSU $+20 \%$ glass fibre composite has shown high sensitivity to the change in load and material combinations. The friction coefficient of PA6 $+20 \%$ mica and PSU +20 glass fibre rubbing against the AISI 4140 steel disc is between $0 \cdot 35$ and $0 \cdot 40$. In rubbing against PPS $+30 \%$ glass fibre their values were between $0 \cdot 25$ and $0 \cdot 30$. Specific wear rate for PA6 + 20\% mica and PSU + 20\% glass fibre composites are in the order of $10^{-13}$ to $10^{-14} \mathrm{~m}^{2} / \mathrm{N}$. Finally, the wear mechanisms are a combination of adhesive and abrasive wear processes. In terms of application, especially in electrical systems, a substantial contribution was provided to extend switch life. Thus, besides robustness, this also ensured safety for the system and the users against undesirable situations.
\end{abstract}

Keywords. Polysulphone; polyamide; polymer; composite; wear; friction; switch life.

\section{Introduction}

Tribology of polymers can be attributed to two main mechanisms, deformation and adhesion. The deformation mechanism involves complete dissipation of energy in the contact area. The adhesion component is responsible for most of the friction of the polymer. This is a result of breaking of weak bonding forces between polymer chains in the bulk of the material and counterface or the transfer of film (Lancaster 1990; Hutchings 1992). Polymers and polymer composites are used in insulators, bushes, sliders and gear materials. Wear damages surface performance of insulating polymers and affects their application performance. PSU (polysulphone) polymers and PA6 (polyamide) are known for their excellent mechanical, electrical, thermal, stability, and UV and gamma radiation resistance (Sarfaty 1983). Very little is reported on the potential of reinforcement in these aspects and evaluate the wear damage on their dielectric and insulating performance (Vishwanath et al 1993). Furthermore, in tribological problems, it is believed that the coefficient of friction can be reduced and wear resistance can be improved by selecting material considering bonds, strength and sharing and rupture of rubbing materials inside and around the contact region (Yamaguchi 1990; Hooke et al

(zaferdemir@anadolu.edu.tr)
1996). For PSU and PA6 polymers, glass fibre and mica are important fillers. Reinforcement of thermoplastics and polymer blends by mica has been the subject of several studies due to its unique set of properties (Mituishi et al 1987; Malik et al 1992; Bose and Mahanwar 2004). Mica has outstanding mechanical, thermal, electrical and chemical properties rarely found in any other product. In the past, a wide range of studies have been carried out on the influence of test conditions, environment and counterface materials on the friction and wear behaviour of polymer and polymer composites. Brentnall and Lancaster (1989) observed that the friction coefficient of polymers rubbing against metals decreases with the increase in load while Yamaguchi (1990) showed that its value increases with the increase in load. The role of counterface material and transfer of film has also been studied for some polymers (Bahadur 2000; Schwartz and Bahadur 2000). Duan et al (2009) studied the effect of frictional heat on tribological behaviour of polyphenylenesulphide (PPS), polyethersulphone (PES) and PSU under dry and different cooling conditions. They concluded that PSU friction coefficient increases with increase in applied load value.

This study aims to explore the influence of test speed, load values and rubbing material's combination on the friction and wear behaviour of PA6 $+20 \%$ mica and PSU $+20 \%$ GFR (glass fibre reinforced) polymer composites used in the 
electrical contact breaker component. Friction and wear tests of the PA6 $+20 \%$ mica and PSU polymer composites vs AISI 316L steel and PPS + 30\% GFR polymer composites were carried out on a pin-on-disc rig and at a dry sliding condition. Tribological tests were conducted at room temperature, under 10,20 and $30 \mathrm{~N}$ loads and at $0.5 \mathrm{~m} / \mathrm{s}$ sliding speeds. For two material combinations used in this investigation, the coefficient of friction shows very little sensitivity to applied load values and large sensitivity to material combinations. Specific wear rate for PA6 $+20 \%$ mica and PSU $+20 \%$ glass fibre composites are in the order of $10^{-13}$ to $10^{-14} \mathrm{~m}^{2} / \mathrm{N}$. Finally, the wear mechanisms are a combination of adhesive and abrasive wear processes.

\section{Experimental}

The pin materials used in this study are commercially available PA6 + 20\% mica and PSU + 20\% GFR polymer composites. The filler GFR is E-type short size randomly orientated glass fibre. Samples of $6 \mathrm{~mm}$ diameter flat-ended pins of PSU $+20 \%$ GFR and PA6 $+20 \%$ mica composite and $5 \mathrm{~mm}$ thickness and $100 \mathrm{~mm}$ diameter discs of PA6 + 30\% GFR were produced by injection moulding. AISI $316 \mathrm{~L}$ steel disc is cut and the surface was grounded. To reduce running-in period, disc surfaces are polished by corundum paper to obtain an average surface roughness of $R_{\mathrm{a}}=1.6-3 \mu \mathrm{m}$. Before each test, pin and disc surfaces are cleaned with alcohol and acetone and thoroughly dried. For tribological tests, a pin-on-disc apparatus connected to a computer is used. During the tests, a transducer mounted on the loading arm measured the friction force. Readings are taken as the average of 30 readings every $60 \mathrm{~s}$. For this purpose, a microprocessor-controlled data-acquisition system is used. Each test was carried out for a sufficient time within the steady-state region. Furthermore, to ensure reliability of the results, each test is repeated thrice. After each test, the mass loss in pin was measured. The scatter in the results is small. Therefore, the average values are taken into consideration. The loss in pin volume is calculated and recorded using density of the corresponding polymer.

\section{Results and discussion}

Figures 1 and 2 show the variation of coefficients of friction with applied load values for PA6 + 20\% mica and PSU $+20 \%$ glass fibre composites against AISI 316L stainless steel and PA $46+30 \%$ GFR discs, respectively. It is clear from these figures that the coefficients of friction values of all tested polymers are not influenced by the change in load. Friction coefficient varies for different rubbing surface materials. Friction coefficient of PA6 $+20 \%$ mica and PSU +20 glass fibre rubbing against the AISI 4140 steel disc is between 0.35 and 0.40 . In rubbing against PPS + $30 \%$ glass fibre, their friction coefficient values are between 0.25 and 0.30 . There is $29 \%$ and $25 \%$ drop in friction coefficients of PA6 and PSU composites, respectively as rubbing

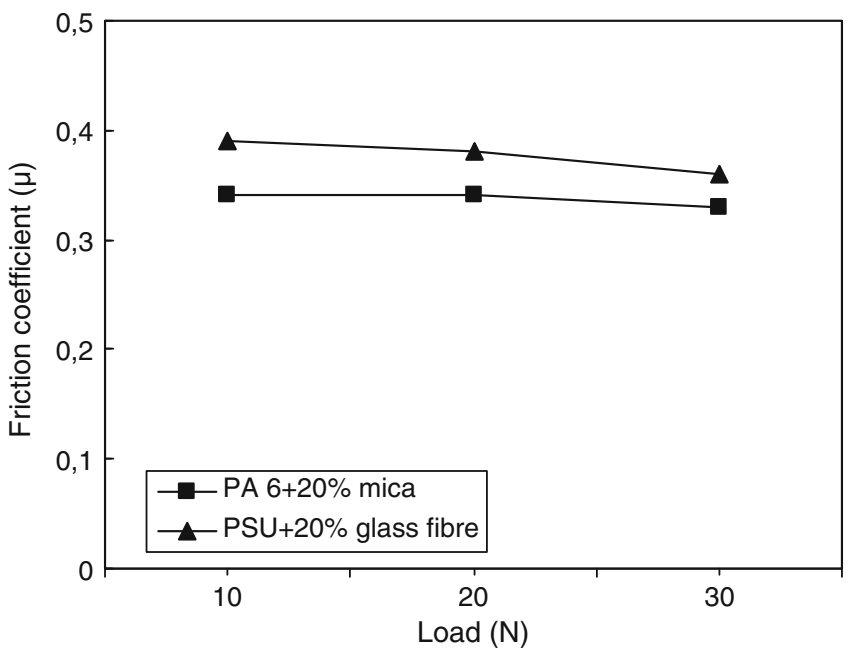

Figure 1. Friction coefficient-load curve for PA6 + 20\% mica and PSU $+20 \%$ glass fibre composites against AISI 316L stainless steel at $0.5 \mathrm{~m} / \mathrm{s}$ sliding speeds.

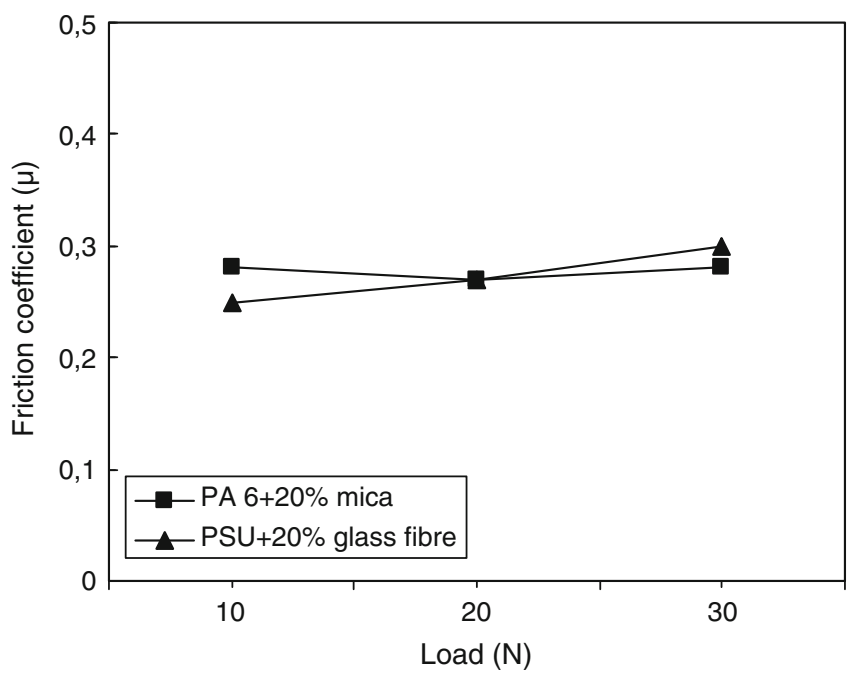

Figure 2. Friction coefficient-load curve for PA6 $+20 \%$ mica and PSU $+20 \%$ glass fibre composites against PPS $+30 \%$ GFR composite at $0.5 \mathrm{~m} / \mathrm{s}$ sliding speeds.

against the AISI $316 \mathrm{~L}$ steel disc in comparison to rubbing against PA $\&+30 \%$ GFR disc. It is known that tribological behaviour of polymers and polymer composites can be associated with their visco-elastic and temperature-related properties. It is known that the sliding contact of two materials results in heat generation at asperities and hence increases the temperature. The amount of rise in temperature is influenced by the amount of heat flow. If the increase in surface temperature is high in comparison to heat deformation temperature of the material, this influences the visco-elastic property which causes softening of the materials. This causes the rubbing of GFR fibres of faced materials or fibre against steel; 
hence reflects the tribological behaviour of materials. Therefore, a drop in the coefficient of friction occurs while rubbing a polymer composite with another polymer composite. Figures 3 and 4 present the variation of specific wear rate with applied load values for PA6 + 20\% mica and PSU + $20 \%$ glass fibre composites against AISI 316L stainless steel and PA $46+30 \%$ GFR discs, respectively. In case of rubbing against steel, both materials have shown sensitivity to change in load values. In case of rubbing against PA6 + 30\% GFR disc, PA6 + 20\% mica composite has shown very little sensitivity to the change in load value while PSU $+20 \%$ GFR has shown large sensitivity to change in load and with an increasing trend which is opposite to its decreasing trend while rubbing against steel disc. This is due to the rubbing of glass fibre to glass fibre. Specific wear rate value

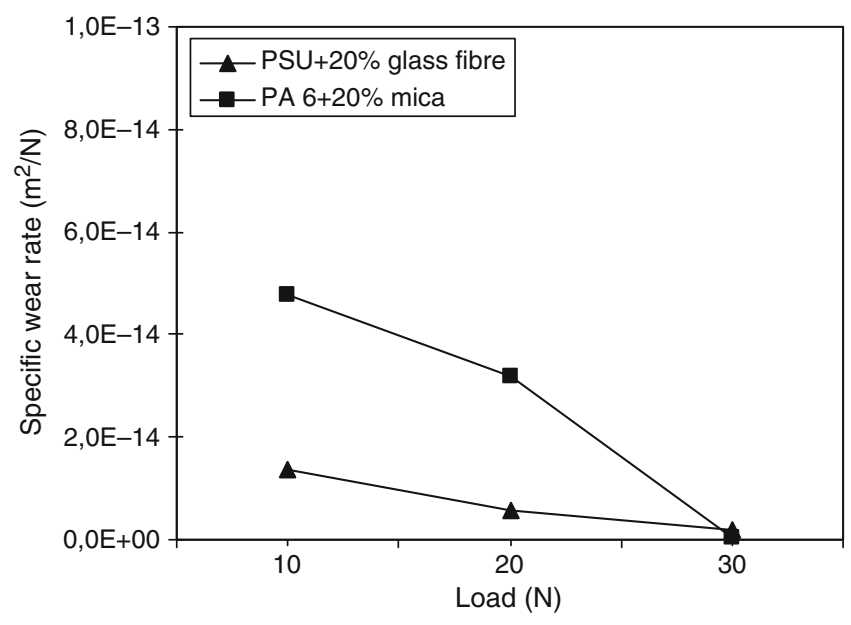

Figure 3. Specific wear rate-load curve for PA6 $+20 \%$ mica and PSU $+20 \%$ glass fibre composites against AISI 316L stainless steel at $0.5 \mathrm{~m} / \mathrm{s}$ sliding speeds.

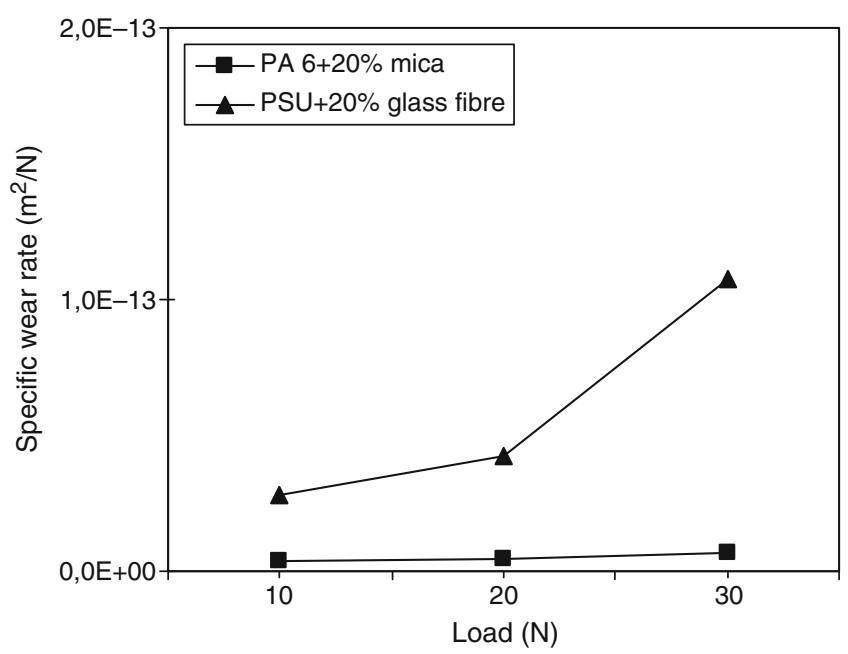

Figure 4. Specific wear rate-load curve for PA6 $+20 \%$ mica and PSU $+20 \%$ glass fibre composites against PPS $+30 \%$ GFR composite at $0.5 \mathrm{~m} / \mathrm{s}$ sliding speeds. of PSU composite is influenced by applied load value and counterface material. Increase in wear rate is associated with the surface layer reaching the softening point of the polymer consequent to high wear rates. The softening of PA6 composite is different from PSU composite due to the difference in heat deformation temperature, which also explains the effectiveness of the formed transfer film. In case of rubbing polymer on polymer, the effectiveness of this film becomes less or disappears due to removal by rubbing fibre. As wear process in polymers involves adhesive and plastic flow, transitions between regions dominated by each of these, commonly lead to changes in wear rate. Furthermore, the results are closely related to structuring characteristics and transfer film formation on the counterpart material. It is also clear that GFR fibres result in some abrasives besides the adhesive wear mechanism. In general, the specific wear rate for PA6 $+20 \%$ mica and PSU $+20 \%$ glass fibre composites are in the order of $10^{-13}$ to $10^{-14} \mathrm{~m}^{2} / \mathrm{N}$. Finally, the wear mechanisms are a combination of adhesive and abrasive wear processes.

\section{Conclusions}

The study of tribological behaviour of $20 \%$ mica-filled polyamide 6 (PA6 + 20\% mica) and 20\% short glass fibrereinforced polysulphone (PA6 + 20 GFR) polymer composites used in electrical applications showed that:

(I) Friction coefficient is only sensitive to material combinations and is not influenced by change in applied load values.

(II) Friction coefficient of PA6 $+20 \%$ mica and PSU +20 glass fibre rubbing against AISI 4140 steel disc is between 0.35 and 0.40 . In case of rubbing against PPS $+30 \%$ glass fibre, their values are between $0 \cdot 25$ and 0.30 .

(III) Specific wear rate for PA6 $+20 \%$ mica and PSU + $20 \%$ glass fibre composites are in the order of $10^{-13}$ to $10^{-14} \mathrm{~m}^{2} / \mathrm{N}$.

(IV) Wear mechanisms are a combination of adhesive and abrasive wear processes.

(V) The studied composite materials provide a substantial contribution to extend switch life of electrical systems. Besides the robustness, it also ensures safety for the system and users against undesirable situations.

\section{References}

Bahadur S 2000 Wear 24592

Bose S and Mahanwar P A 2004 J. Min. Mater. Char. Eng. 323

Brentnall A B and Lancaster J K 1989 Proc. Wear Mater. Cong. ASME 596

Duan Y, Cong P, Liu X and Li T 2009 J. Macromol. Sci. B48 604

Hooke C J, Kukureka S N, Liao P, Rao M and Chen Y K 1996 Wear 20083

Hutchings I M 1992 Tribology, friction and wear of engineering materials (London: Edward Arnold) p. 51

Lancaster J K 1990 Wear 141159 
Malik T M, Faroqui M I and Vachet C 1992 Polym. Compos. 13 174

Mituishi K, Kodama S and Kawasaki H 1987 J. Macromol. Sci. Phys. 26479

Sarfaty I W 1983 J. Polym. Sci. Polym. Symp. 70129
Schwartz C J and Bahadur S 2000 Wear 237261

Vishwanath B, Verma A P and Rao C V S 1993 Wear 16793

Yamaguchi Y 1990 Tribology of plastic materials: their characteristics and applications to sliding components (Amsterdam: Elsevier) 